\title{
Factors of Economic Innovative Development: Cross-Country Evidence
}

\author{
Larionova Natalia
}

Varlamova Julia

Kazan Federal University

\author{
Doi:10.5901/mjss.2014.v5n18p349
}

\begin{abstract}
During last decade an increase of state outlays for investigations and developments that promote innovative development of foreground economical branches has taken place, various methods of firms' innovative activities stimulating are being applied. In our survey innovative development is considered as a complex of three components: R\&D sphere, degree of real sector development, institutional environment. The aim of our investigation is to check hypothesis of innovation, economic and institutional environment influence on innovative production of economy. The object of investigation is innovative production of 35 OECD countries in 2010.
\end{abstract}

Keywords: innovative development, $R \& D$, institutional environment

\section{Introduction}

Researches underline a necessity to improve law, organizing, institutional conditions of activity and to create preferences for innovatively developing companies. Recent investigations of barriers preventing innovative development of companies and whole country have shown the need to realize policy to maintain an effective innovative environment (Melnik et al., 2013, 2014). Thus there is a necessity to analyze existing factors able to influence on economical innovative development, their significance and impact estimation, and to determine strategic measures for innovative activity growth.

Thanh and Kam Ki (2014) investigate the impact of academic research on high-tech manufacturing growth. The investigation includes the period of $1991-2005$ and analyses activity of 28 companies. With the help of econometric analysis it has been proved, that impact differential between academic and government R\&D is statistically significant.

Fagerberg, Srholec (2008) analyze interrelation between national innovative system and economic development. The main research method is factor analysis of 175 countries data. The empiric analysis has shown that developed innovative system is a key factor for countries of catching-up development. Steady, statistically significant interrelation between GDP per capita and innovative system development has been found.

Sleuwaegen, Boiardi (2014) analyze creative workers as the main element of regional innovations. They investigate such index as human sources and technological infrastructure.

Work of Hsu, Tian, Xua (2013) investigate financial market influence on technological innovations. They are positively influenced by developed fund market, at the same time there is negative interrelation with the level of credit market development. Gorodnichenkoy, Schnitzer (2013) also explore financial market and answer how limitations will influence over innovating activity of firms. Mahroum, Aslaleh (2012) use an index method as the basis of investigation with constructing the AC/DC model. Hecker (2005) studied employment and human sources in innovative sphere.

\section{Methodology}

The conducted literature review has shown that there is a great amount of methods to assess the degree of innovation development. They are: econometric modeling, factor analysis, integral indices, and analysis of separate criteria complex. Each of these methods has its pros and cons, but they are used as tools in companies' behavior investigating. One of the most popular methods is composite indices constructing. But in this case there is one important minus as every firm includes different criteria in these indices and this significantly limits comparing possibilities. Another method is econometric models constructing. It is useful for definition of the most important indicators of innovative development degree and in the sphere of prediction. But the main defect is in determination of resulting indicator.

The purpose of our survey is to check hypothesis of innovation, economic and institutional environment influence on innovative production of economy. As a method of hypothesis verification econometric models were used. Choosing 
independent variables for our model we relied on experience of previous researches and were restricted by set of indicators available in statistics database. Besides we have investigate main indices reflecting rates of innovative development, among them are Global innovation index (INSEAD), Global index of innovations (GII BCG), Index of global competitiveness (and its subindex of "innovations") (World Economic Forum), Index of ability to innovations. Analysis of their structure allows identifying the most significant criteria of economic innovative development. In each of these indices there are indicators characterizing development level of economy, institutions and various marks of innovative sectors.

Sources for analyses of economic innovative development were indicators from databases of OECD (OECD Library, 2014), World Bank (2014), Doing Business Report (2010) and Human Development Report (2010). For model constructing we have used the selection compiled according to official statistics data. This suggests distinguishing some macroeconomic criteria which are hypothetically able to influence on bank activity.

At the initial stage it was necessary to allocate some complex indicators characterizing and influencing innovative development of economic system. They give an idea of economic innovativeness degree comparing with indicators characterizing main macroeconomic development parameters and institutional environment.

While regression analyzing as explained variables two parameters were chosen:

1) HIMN - value added high tech and medium-high tech (total);

2) HTexport - export high tech (total).

Regressors in the models were divided into three groups according to checking hypothesis:

1. R\&D sphere includes (Technology and Industry Outlook, 2010):

1) GERD - government expenditure on R\&D as a percentage of GDP.

2) TopUNI - amount of the top 500 universities per million US dollars of GDP at PPP that allows to cause to one base countries with different scales and levels of economic development.

3) PubExp - Public expenditure on R\&D is the sum of higher education expenditure on R\&D and government expenditure on R\&D (GERD) and is expressed as a percentage of GDP.

4) BusExp - Business enterprise expenditure on R\&D for many OECD countries are the base for R\&D sector development as innovations in most cases are intruded in goods and services production

5) Publ - Publications. It is determined by the quantity of publications in the $25 \%$ of most influential world's scholarly journals. This indicator is calculated per million US dollars of GDP at PPP to level scale and rate dependence of country's economy development.

6) Tradem - trademarks are used by firms to mark and distinguish applied technological, marketing or service innovation reflected in end-product. The number of trademarks applied for over the 2007-09 period is expressed per billion US dollars of GDP at PPP.

7) TertEdu - The adult population with tertiary educational attainment. This parameter takes into consideration adults from 25 to 64 years old with a university degree, vocational qualifications, or advanced research degrees of doctorate standard.

8) S\&Temp (HTM, 2010) - employed in science and technology. It complements the previous indicator of human resource development in R\&D. It depicts not only all high educated labour resources but also determines quantity of professionals and technicians.

9) Patents - are direct determinant of R\&D development as they are idea sources for elaborating and introduction into real sector of economy.

2. The level of real economy sector development influences directly on R\&D sector as the majority of ideas created in R\&D are forwarded to making or improvement of technologies, products, services, realized in real sector. Low level of real sector development leads to the situation when innovations created in R\&D cannot be applied technologically in production. On the other hand high level of real sector development stimulates elaboration of new ideas that can be firm's competitive advantage. The main criteria in this sphere are:

1) ProdGR - Annual growth rate of labour productivity (\%) is counted as GDP per hour worked, in current US dollars at purchasing power parity (PPP). It characterizes economical growth based on increase of labour productivity as the main production factor and that has its minuses.

2) CPI - Consumer Price Index - the key criterion of economy stability. It allows distinguishing whether main economical agents can make middle- and long-term decisions, orientating on economical development forecasts. This is especially important for R\&D sector development as investments into innovations are often conjugated with payback long period. The index is annual rate of price growth.

3) Unemp - Harmonised Unemployment rate - the number of unemployed persons as a percentage of the labour force (the total number of people employed plus unemployed). This criterion characterizes the situation at labour market wholly and complements human fund criteria. 
4) Popul - average annual population amount of all ages.

5) GovDebt - government debt

6) IR - long time interest rest characterizes stability of credit sphere development.

7) GDPgr - growth rate of GDP

8) GNI - gross national income

3. State of institutional environment

Institutional environment is usually concerned as a complex of politic and economical conditions needed for provision of economical agents successful functioning. On probation economical characteristics of institutional environment can be divided into three units:

- Economical liberties (free trade, investment, fiscal, financial freedoms, free labour, freedom from corruption);

- Developed system of provision of contract rights, property, investors interests protection;

- Absence of administrative barriers in firm's registration and liquidation, licenses and permissions obtaining, taxes payment, various kinds of business activities control.

We focus our analyses on the third unit and base it on statistical data of Doing Business report (2010). We have analyzed the following criteria:

1) Starting a business: ProcSB - procedures (number), CostSB - cost (\% of income per capita);

2) Registering property ProcProp - procedures (number), TimeProp - time (days), CostProp - cost (\% of income per capita);

3) GetCred - getting credit (rank);

4) Taxes: TaxNum - number, TaxRate - total rate

5) Export: ExpTime - time (days);

6) Enforcing contracts: ECTime - procedures (number), ECCost - cost (\% of claim).

During the work a lot of specifications were constructed. As a result we have chosen models with the highest explaining ability for each of investigating aspects influencing on economical innovative productiveness. For creation of regression multiple equations it was necessary to logarithm number of variables which could wittingly have only positive value and which were estimated generally with the help of relative indicators. Logarithm use in equations doesn't make significant difference, but provides quality improvement of regression model.

\section{Results}

In tables coefficients of arguments are depicted and general quality of regression multiple equations are demonstrated.

Table 1. Innovative environment

\begin{tabular}{l|cc|cc} 
& \multicolumn{2}{|c|}{ InHTexport } & InHIHT & \\
\hline InPubExp & $-2,082^{* *}$ & $(0,844)$ & $-0,235$ & $(0,817)$ \\
InTopUNI & $-0,352$ & $(0,469)$ & 1,092 & $(1,599)$ \\
InBusExp & $0,402^{*}$ & $(0,220)$ & $0,912^{* *}$ & $(0,419)$ \\
InTradem & $-0,135$ & $(0,291)$ & $-2,022^{* *}$ & $(0,958)$ \\
InPatents & $0,865^{* * *}$ & $(0,146)$ & $0,782^{* * *}$ & $(0,199)$ \\
GERD & 0,185 & $(0,333)$ & 0,514 & $(0,640)$ \\
TertEdu & $-0,002$ & $(0,004)$ & $0,010^{*}$ & $(0,005)$ \\
SnTEmp & $0,0153^{* *}$ & $(0,007)$ & $-0,001$ & $(0,005)$ \\
InPubl & 0,505 & $(1,169)$ & $-2,804^{*}$ & $(1,527)$ \\
\hline \multicolumn{1}{c|}{$\mathrm{R}^{2}$} & 0,761 & & 0,786 &
\end{tabular}

The models show that for two investigating related variables patents quantity, business expenditure are significant. It can be noted that these both indicators are directly connected with innovation introduction in real business sphere. Thus expense increase will positively influence on innovations. At the same time state expenses have statistically strong negative interrelation with innovative products' export that corresponds to other authors' researches (L.Thanh and T. Kam $\mathrm{Ki})$. In the second model for InHIHT there is interrelation with adult population with tertiary educational attainment - one of human resources quality indicators in country. It distinguishes high-qualified labour force that can potentially work in R\&D sector based on high-educated and qualified labour resources and mentions the necessity of investments for human resources forming in $R \& D$ sphere. 
Table 2. Economical environment

\begin{tabular}{l|cc|cc} 
& \multicolumn{2}{|c|}{ InHTexport } & InHIHT \\
\hline InGNI & $2,314^{* *}$ & $(0,706)$ & 2,482 & $(1,584)$ \\
InPopul & $0,642^{* *}$ & $(0,229)$ & $-0,822^{* *}$ & $(0,359)$ \\
InGovDebt & 0,170 & $(0,143)$ & $1,179^{* * *}$ & $(0,283)$ \\
GDPgr & $-0,060$ & $(0,081)$ & $0,484^{* *}$ & $(0,223)$ \\
IR & $-0,326^{* *}$ & $(0,122)$ & $-0,148$ & $(0,327)$ \\
ProdGR & $0,371^{*}$ & $(0,189)$ & 0,756 & $(0,550)$ \\
Unemp & $-0,036$ & $(0,050)$ & $-0,016$ & $(0,149)$ \\
CPI & $-0,047$ & $(0,187)$ & $0,971^{*}$ & $(0,501)$ \\
\hline \multicolumn{1}{c|}{$\mathrm{R}^{2}$} & 0,793 & & 0,703 &
\end{tabular}

The analysis has distinguished strong statistical interrelation between innovative and economical development. For export it is GNI and for InHIHT they are increase rate of GDP and Government Debt. Besides we have got additional confirmation of qualitative human resources necessity as interrelation between labour productiveness and InHIHT was dedicated. Increase of interest rate will negatively influence on export of high-tech products and this should be concerned in monetary policy.

Table 3. Institutional environment

\begin{tabular}{l|cc|cc} 
& \multicolumn{2}{|c|}{ InHTexport } & InHIHT \\
\hline ECTime & $-0,001$ & $(0,001)$ & $-0,004^{*}$ & $(0,002)$ \\
ECCost & $0,080^{* *}$ & $(0,025)$ & 0,032 & $(0,062)$ \\
ProcSB & 0,099 & $(0,131)$ & $-0,149$ & $(0,205)$ \\
CostSB & 0,084 & $(0,058)$ & $0,252^{*}$ & $(0,124)$ \\
ProcProp & 0,079 & $(0,121)$ & $-0,009$ & $(0,255)$ \\
TimeProp & $0,008^{* *}$ & $(0,004)$ & 0,004 & $(0,006)$ \\
CostProp & 0,125 & $(0,089)$ & 0,111 & $(0,173)$ \\
GetCred & $-0,022^{* *}$ & $(0,009)$ & $-0,020$ & $(0,019)$ \\
TaxNum & $-0,006$ & $(0,028)$ & $-0,039$ & $(0,050)$ \\
TaxRate & $0,058^{* *}$ & $(0,023)$ & 0,003 & $(0,059)$ \\
ExpTime & $-0,221^{* *}$ & $(0,091)$ & $-0,053$ & $(0,141)$ \\
\hline \multicolumn{1}{c}{$\mathrm{R}^{2}$} & 0,677 & & 0,53 &
\end{tabular}

Statistically significant strong inverse economical interrelation was shown by export time and getting credit. The biggest divergences were in institutional environment analysis. So a lot of investigated factors influence on innovative products' export, but don't influence on added cost. It is connected with the fact that while analyzing institutional environment we investigate factors revealed to administrative barriers and they are important at the initial stages of companies' work, so they can be indirectly taken into account in full products cost (clear export cost), but they are not included into added cost of innovative products.

The divergence of results is connected with the fact that in the first regression the focus is on the full cost of innovative products' export and in the second one it is on added cost of high-tech products. As the analysis has shown in some cases the improvement of situation in the sphere of innovation stimulating can lead to reduce of such products' export, therefore the first indicator has inverse interrelation with state expenses. This should be taken into consideration while innovative policy performing.

\section{Discussion}

The research results are useful practically as they reflect strong interrelation between separate economical factors and economy innovative development. The understanding of investigated interrelations can help to create innovative policy providing successful development of economical system and its competitiveness increase. Still there are possibilities to advance results of the proposed models and find more and more noticeable indicators (especially in institutional sphere). 


\section{Conclusion}

In our research we have investigated influence of various factors on innovative development of economic system. The performed econometric analysis allowed distinguishing economic environment factors influencing innovative sphere. The results of our analysis have shown that human resources have statistically significant influence (it is confirmed by positive interrelation between both related variables and such indicators as InPopul, S\&TEmp). Besides, there is a positive interrelation with patents quantity. This means that for economy competitiveness increasing it is necessary to stimulate human resources development as by improving own resources so as by attracting resources from the outside. The results of economic environment analysis has also confirmed the importance of such a criteria as human resources (there is strong interrelation with InPopul indicator).

Next important factor influencing innovative productiveness is expenses for innovations. They are the main method of innovative activeness stimulating by state. In our models positive influence on innovative production is shown by business expenditure on innovations. While public expenditure on innovations criterion has negative interrelation with resulting argument (InHTexport). It can be explained by the fact that state interruption reduces export incentive and innovative products stay in country. Thus it is necessary to create conditions for investment into elaboration, production and introduction of innovative product.

The analysis of real sector has proved our hypothesis that more developed economic environment influences positively on innovations. The most important characteristic are criteria connected with economic development and management conditions (GDPgr) influencing on possibility of resources getting (InPopul, CPI, IR). It is important to stimulate firms' innovative activity, to create conditions for private investments. It is important to understand that all efforts in innovative activity developing must be provided by necessary mechanisms of innovations spread and exchange.

\section{Acknowledgements}

This work was funded by the subsidy allocated to Kazan Federal University for the state assignment in the sphere of scientific activities.

\section{References}

Doing Business (DB), 2010. World Bank. Full Report, pp. 231

Fagerberg J. and M. Srholec, 2008. National innovation systems, capabilities and economic development. Research Policy 37, pp. 1417-1435

Gorodnichenkoy Y. and M. Schnitzer, 2013. Financial constraints and innovation: Why poor countries don't catch up. Journal of the European Economic Association. European Economic Association. vol. 11(5), pp. 1115-1152

Hecker D., 2005 High-technology employment: a NAICS-based update. Monthly Labor Review. July 2005 pp. 57-72

High Technology Manufacturing (HTM), 2010. The New Zealand Sector Report. Ministry of Business, Innovation and Employment, pp.132

Hsu P., Tian X. and Y.Xua, 2013. Financial development and innovation: Cross-country evidence. Journal of Financial Economics (JFE). http://papers.ssrn.com/sol3/papers.cfm?abstract_id=1745682 (Accessed on June 20, 2014)

Human Development Report (HDR) 2010. Published for the United Nations Development Programme (UNDP), pp.238

Mahroum S. and Y.Aslaleh, 2012. Measuring Innovation Efficacy: An Operational Framework for Mapping and Measuring Innovation Capacity and Performance of Countries. Faculti\&Research. Working Paper INSEAD, pp. 41

Melnik, A. and A. Sadriev, 2013. Challenges and Opportunities for the Energy Clusters Formation. World Applied Sciences Journal. 27, pp.194-197

Melnik A., Ermolaev K. and N. Antonova, 2014. Stages in formalizing energy conservation and efficiency management in industrial enterprises. Mediterranean Journal of Social Sciences 5 (12), pp. 173-176

OECD Library. Statistics. http://www.oecd-ilibrary.org/statistics (Accessed on June 5, 2014)

Sleuwaegen L. and P.Boiardi, 2014.Creativity and regional innovation: Evidence from EU regions. Research Policy. http://www.sciencedirect.com/science/article/pii/S0048733314000535 (Accessed on June 20, 2014)

Technology and Industry Outlook, 2010. OECD Science. OECD Publishing, pp.293

Thanh L. and T. Kam Ki, 2014. Impacts of academic R\&D on high-tech manufacturing products: tentative evidence from supercomputer data Studies in Higher Education. http://dx.doi.org/10.1080/03075079.2013.865160 (Accessed on June 17, 2014)

The World Bank. Database. http://data.worldbank.org/indicator (Accessed on June 5, 2014) 
